\title{
Premature Birth Detection from EHG signals
}

\author{
Ahmet Sağlam ${ }^{*}$, Ümit Şentürk ${ }^{2}$, İbrahim Yücedağ ${ }^{3}$ \\ $1^{1 *}$ Amasya University, Merzifon Vocational School, Amasya, Turkey, (ORCID: 0000-0002-2616-8253), ahmet.saglam@amasya.edu.tr \\ 2 Abant Izzet Baysal University, Faculty of Engineering, Departmant of Computer Engineering, Bolu, Turkey, (ORCID: 0000-0001-9610-9550), \\ umit.senturk@ibu.edu.tr \\ ${ }^{3}$ Duzce University, Faculty of Engineering, Departmant of Computer Engineering, Duzce, Turkey, (ORCID: 0000-0003-2975-7392), ibrahimyucedag@duzce.edu.tr
}

(1st International Conference on Applied Engineering and Natural Sciences ICAENS 2021, November 1-3, 2021)

(DOI: 10.31590/ejosat.1014179)

ATIF/REFERENCE: Sağlam, A., Şentürk, Ü. \& Yücedağ, İ. (2021). Premature Birth Detection from EHG signals. European Journal of Science and Technology, (28), 1283-1287.

\begin{abstract}
Premature birth is one of the major problems worldwide. Different methods have been researched and used to detect preterm birth from past to present. The most commonly used ones are; The tocodynamometer device is Transvaginal Cervix Length, Bishop Score and ElectroHysteroGram (EHG) signal. Studies have shown that it is widely used in estimating the risk of preterm birth using EHG signals. In the studies, feature extraction was made from EHG signals and preterm birth risk was estimated with various regression algorithms. In this study, the SMOTE algorithm in the methods used in the detection of preterm birth with EHG signals was examined and compared. As a result, it has been seen that the SMOTE algorithm is effective in reaching the result in all methods. In this study, the best result was obtained with the $\mathrm{CNN}$ algorithm.
\end{abstract}

Keywords: EHG, preterm birth, machine learning, deep neural networks, CNN.

\section{EHG sinyallerinden Erken Doğum Tespiti}

\section{$\ddot{O} z$}

Erken doğum dünya genelinde büyük problemlerden biridir. Geçmişten günümüze kadar erken doğumu tespit etmek amacıyla farklı yöntemler araştırılmış ve kullanılmıştır. En yaygın kullanılanları ise; Tokodinamometre cihazı, Transvajinal Serviks Uzunluğu, Bishop Skoru ve ElectroHysteroGram (EHG) sinyalidir. Yapılan araştırmalar, EHG sinyalleri kullanılarak Erken doğum riskinin tahmin edilmesinde yaygın olarak kullanıldığı gözlenmiştir. Çalışmalarda, EHG sinyallerinden öznitelik çıkartımı yapılıp, çeşitli regresyon algoritmaları ile Erken doğum riski tahmin edilmiştir. Bu çalışmada, EHG sinyalleri ile erken doğum tespitinde kullanılan yöntemlerde SMOTE algoritması incelenmiş ve kıyaslaması yapılmıştır. Sonuç olarak tüm yöntemlerde SMOTE algoritmasının sonuca ulaşmada etkili olduğu görülmüştür. $\mathrm{Bu}$ çalışmada, en iyi sonuç $\mathrm{CNN}$ algoritması ile elde edilmiştir.

Anahtar Kelimeler: EHG, erken doğum, makine öğrenmesi, derin sinir ağları, CNN.

\footnotetext{
* Corresponding Author: ahmet.saglam@amasya.edu.tr
} 


\section{Introduction}

The average gestation period in humans is between 37 and 42 weeks. Births occurring between these weeks are called term births (Degbedzui \& Yuksel, 2020). Preterm birth includes births between 24 and 37 weeks. Births exceeding 42 weeks are defined as postterm births (Callahan \& Caughey, 2013). According to the data of the World Health Organization, 1 out of every 10 babies or 15 million babies a year are born prematurely. This is a serious problem, as preterm birth accounts for approximately $50 \%$ of perinatal deaths of infants (Kenny \& Myers, 2020). According to the data of the Ministry, it is stated that this situation is more than 180 thousand every year in our country. Approximately 7,500 of these babies die (Alyanak, 2020).

The inadequacy of methods used to accurately diagnose preterm birth remains one of the biggest unresolved obstetric problems (Lucovnik at al., 2016). Although the estimation of preterm birth is a very difficult task, it is important to detect it as early as possible (Yochum at al., 2016).

However, estimating preterm birth based on these factors alone is far from certain. Analysis of an electromyogram (EMG) of the uterus recorded from the abdominal wall of a pregnant woman is used to better predict preterm delivery. EMG aka ElectroHysteroGram (EHG); consists of signals resulting from discontinuous bursts of action potential due to spontaneous electrical discharges from the uterine muscle (Fele-Žorž at al., 2008). It has been found that EHG records can diagnose labor more accurately than other traditional clinical methods by applying different estimation methods to predict preterm labor (Jager at al., 2018; Maner at al., 2003).

\subsection{Uterine Electrohsterograph (EHG)}

Uterine Electrohsterograph (EHG) provides a measurement of abdominal wall deformations with the effect of uterine contractions. It measures only the rate at which contractions occur and is very sensitive to abdominal wall movements (Léman at al., 1999). EHG is the signal recorded on the abdominal surface and represents the electrical activity that triggers the mechanical contraction of the myometrium (Alamedine, 2015). The EHG records the electrical activity of uterine muscle cells and therefore reflects the direction of electrical control that induces contractile activity in the uterus (Muszynski, 2019).

In the context of EHG analysis, raw signals are obtained from the myometrial muscle using bipolar electrodes attached to the abdominal surface (Greenough, 2013). The results showed that EHG may differ from woman to woman. This depends on whether she will give birth on time or prematurely (Idowu, 2017). Raw EHG signals need preprocessing before analysis or classification. Preprocessing may include filtering, noise removal, wavelet shrinkage or transformation, and automatic detection of bursts (Maner at al., 2003; Léman at al., 1999, Verdenik at al., 2001).

\subsection{Related Studies}

Biomedicine is the application of engineering principles to biology and medicine to improve the quality and effectiveness of patient care. Although the studies on the field are based on many years, studies using machine learning algorithms of EHG signals have gained intensity in recent years.

Khalil and Duchene (2000), presented a sequential detection/classification approach applied to uterine EMG in their study. They stated that the dynamic cumulative sum (DCS) algorithm gave successful results. Euliano et al. (2013), compared TOCO, EHG, and alternative invasive intrauterine pressure catheter (IUPC) methods. The study was conducted with data from 73 subjects and EHG gave better results than other methods in terms of Contractions Consistency Index (CCI). Alexandersson (2015), created a database to provide public access to 16-electrode EHG data in his study. In the study, 122 EHGs belonging to the years 2008-2010 were recorded in Iceland. These records showed that EHG data, a pregnant woman's body mass index, age, and obstetric history can influence the frequency components of contractions.

Ye-Lin et al. (2014), extracted 11 features from EHG signals. These properties are spectral, temporal, and nonlinear. They investigated the classification performance with these 11 extracted features. 2-fold cross-validation, repeated 50 times, was applied across 3 classifiers, including Linear Discriminant Analysis (LDA), Quadratic Discriminant Analysis (QDA), and SVM with RBF kernel function. As a result of the study, the QDA classifier gave the best classification performance with $92.2 \%$ success. Ahmed et al. (2017), determined that the multivariate multiscale fuzzy entropy (MMFE) algorithm is superior to the multivariate multiscale entropy (MMSE) in both synthetic and real EHG signals. Chen and Hao (2017), presented a new method for feature extraction and classification of EHG signals based on Hilbert-Huang transform (HHT) and extreme learning machine (ELM).

The study of Idowu (2017), included the records of 262 women who gave birth in the normal period and 38 women who gave birth prematurely. Innovative signal processing techniques and the application of machine learning algorithms in the analysis of EHG signals are important in estimating the risk of preterm birth. In his study, Levenberg-Marquardt trained Feed Forward Neural Network, Radial Basic Function Neural Network, and Random Neural Network classifiers were used. As a result, 91\% sensitivity and $84 \%$ specificity values were obtained. The average error rate is $12 \%$. Acharya et al. (2017), made a new proposal for automatic prediction of pregnant women who will give birth prematurely by using EHG signals. Eight different features were extracted in the study. These extracted features were analyzed with the vector machine (SVM) classifier for automatic differentiation and as a result, 96.25\%, 95.08\% sensitivity, and $97.33 \%$ specificity were obtained.

Muszynski (2019), examined the estimation of the risk of preterm birth by analyzing electrical parameters from EHG. The results obtained make it possible to improve the estimation of the risk of preterm birth relative to routinely used instruments. Degbedzui and Yüksel (2020), proposed a new method for diagnosing preterm labor without treatment based on the classification of Electrohysterography (EHG) signals. By constructing elements of a feature vector representing the timevarying spectral content of the EHG signal, the centroid frequencies of the frames were calculated. It has been shown that the proposed approach outperforms other methods and can be used effectively in the classification of EHG signals for termpreterm diagnosis.

\section{Material and Method}

In the study, Physionet's Term-Preterm ElectroHysteroGram DataBase (TPEHG DB) online signal database created by FeleŽorž et al. (2008) was used. The data set was created between 
1997 and 2005. The records were recorded at the 22nd gestational week and 32nd gestational week of pregnant women. General information about the data set is given in Table 1.

Table 1. Birth information

\begin{tabular}{|c|c|c|}
\hline & Quantity & Percentage(\%) \\
\hline Preterm birth & 38 & 12,7 \\
\hline On-Time & 262 & 87,3 \\
\hline Total & 301 & 100,0 \\
\hline
\end{tabular}

The data set consists of 300 records. While 38 of these records are preterm births, 262 are normal birth records. Each recording consists of 30 minutes of contractions.

Raw EHG signals need preprocessing before analysis or classification During the preprocessing, filtering was applied to the raw data and the base correction was provided and the noise caused by the noise was removed. The steps performed during the study are given in Figure 1. The chart showing the method used in the study is as follows.

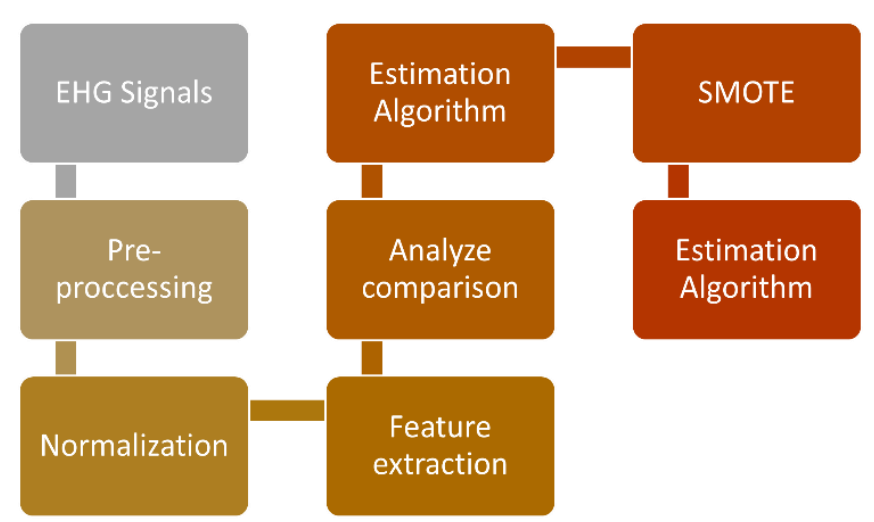

Figure 1. The chart the method used in the study

\section{Results and Discussion}

First, raw data were prepared. The Noise was reduced by base correction and normalization was applied. The features used in the literature were examined and related features were prepared. The results were obtained by using the prepared features and estimation algorithms. The irregularity in the data set was removed by using the SMOTE algorithm, and the estimation algorithms were performed again and the results were compared. The attributes used are listed in Table 2.

Among the attributes given in Table 2, Median Frequency, Peak Frequency, Root Mean Square Level, Sample Entropy and Shannon Entropy have been used in different previous studies. Average Frequency, Peak Magnitude RMS ratio, Band Power, Power Bandwidth and Log Energy Entropy were tested in this study.
Table 2. Prepared Attributes

\begin{tabular}{|l|}
\hline \multicolumn{1}{|c|}{ Attributes } \\
\hline Average Frequency \\
\hline Median Frequency \\
\hline Peak Frequency \\
\hline Peak Magnitude RMS ratio \\
\hline Root Mean Square Level \\
\hline Band Power \\
\hline Power Bandwidth \\
\hline Sample Entropy \\
\hline Shannon Entropy \\
\hline Log Energy Entropy \\
\hline
\end{tabular}

Before the comparison of the estimation algorithms used in the study, the data set resulting from the application of the SMOTE algorithm is given in Table 3 .

Table 3. Birth Information after SMOTE algorithm

\begin{tabular}{|l|c|c|}
\hline & Quantity & Percentage(\%) \\
\hline Preterm birth & 304 & 53,71 \\
\hline On-Time & 262 & 46,29 \\
\hline Total & 566 & 100,0 \\
\hline
\end{tabular}

After the applied SMOTE algorithm, the unbalanced data set was tried to be equalized. After the SMOTE algorithm, the preterm birth rate, which was $12 \%$, increased to $53.71 \%$, and proportionality was approached. The results obtained as a result of the estimation algorithms are compared in Table 4.

Table 4. Results of the estimation algorithms used

\begin{tabular}{|l|c|c|}
\hline \multirow{2}{*}{ Naive Bayes } & \multicolumn{2}{|c|}{ Classified Instances } \\
\cline { 2 - 3 } & Normal Dataset & SMOTE \\
\hline SVM & $29,33 \%$ & $62,37 \%$ \\
\hline Kstar & $87,33 \%$ & $65,19 \%$ \\
\hline Random Forest & $78,33 \%$ & $85,34 \%$ \\
\hline Decision Table & $87,33 \%$ & $87,28 \%$ \\
\hline KNN & $87,33 \%$ & $73,50 \%$ \\
\hline CNN & $80,00 \%$ & $84,10 \%$ \\
\hline
\end{tabular}

When the algorithms used in Table 4 are examined, the best result is CNN (Convolution Neural Network) algorithm with 87.67\%, while SVM, Random Forest, and Decision Table algorithms take second place with a success rate of $87.33 \%$. It is also observed that after the SMOTE algorithm, it improves the result in algorithms other than Decision Table and SVM algorithms. As a result of the SMOTE algorithm, the best performance is in the CNN algorithm with $93.10 \%$. While Random Forest ranked second with a success rate of $87.28 \%$, the rate dropped significantly after the SVM algorithm and the SMOTE algorithm. 


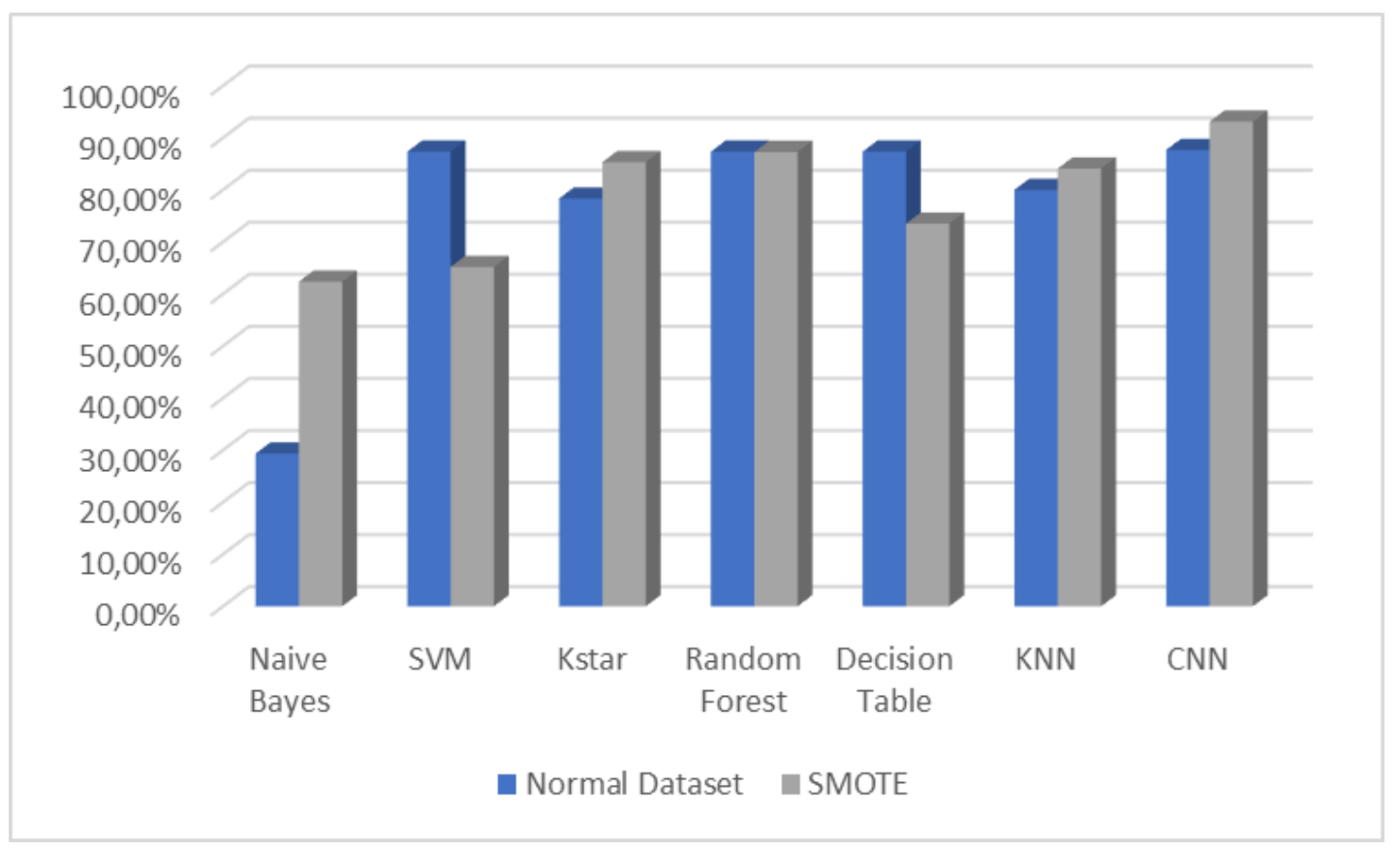

Figure 2. The result graph of the prediction algorithms used

When Figure 2 is examined, it is seen that the SMOTE algorithm, which improves all algorithms except the SVM algorithm, improves the Naive Bayes algorithm the most. There is no visible change in the Random Forest algorithm. When the graph is examined, the best performance in the Normal data set was SVM, Random Forest, Decision Table and CNN algorithms, while the CNN algorithm gave the best result as a result of the SMOTE algorithm.

\section{Conclusions and Recommendations}

In the literature review, linear methods were superior to nonlinear methods in differentiating normal birth and preterm birth based on non-stationary uterine EMG signals.

Despite this, it seems that there is still a large area of study to improve the accuracy of the prediction of preterm birth, which can significantly increase the survival rates of preterm babies.

In the study, EHG signals were preprocessed, and then the results were obtained with the extracted features and estimation algorithms. In addition, the SMOTE algorithm was used to eliminate the irregularity in the data set and the results were analyzed in the re-estimation algorithms. It has been seen that the SMOTE algorithm improves all algorithm results. As a result of the analysis, it was determined that the $\mathrm{CNN}$ algorithm gave the best result. The created CNN Algorithm is a single LSTM algorithm. As the number of LSTMs increases, its performance needs to be investigated.

\section{References}

Acharya, U. R., Sudarshan, V. K., Rong, S. Q., Tan, Z., Lim, C. M., Koh, J. E., ... \& Bhandary, S. V. (2017). Automated detection of premature delivery using empirical mode and wavelet packet decomposition techniques with uterine electromyogram signals. Computers in biology and medicine, 85.

Ahmed, M. U., Chanwimalueang, T., Thayyil, S., \& Mandic, D. P. (2017). A multi variate multiscale fuzzy entropy algorithm with application to uterine EMG complexity analysis, Entropy, 19(1), doi: 10.3390/e19010002.

Alamedine, D. (2005). Election of EHG parameter characteristics for the classification of uterine contractions, PHD thesis, Université Libanaise.

Alexandersson, Á. (2015). Conceiving, compiling, publishing and exploiting the 'Icelandic 16-electrode EHG database', PHD Thesis. Háskólinn í Reykjavík.

Alyanak, Ç. M. (2020). Türkiye'de her 10 bebekten biri hayata erken başliyor, https://www.aa.com.tr/tr/saglik/prof-dr-kocturkiyede-her-10-bebekten-biri-hayata-erken-basliyor /1306225 (erişim Kas. 17, 2020).

Callahan T. \& Caughey, A. B., (2013). Obstetrics \& Gynecology Sixth Edition, Lippincott Williams \& Wilkins: U.S.A.

Chen L. \& Hao, Y. (2017). Feature Extraction and Classification of EHG between Pregnancy and Labour Group Using Hilbert-Huang Transform and Extreme Learning Machine, Comput. Math. Methods Med., doi: 10.1155/2017/7949507.

Degbedzui, D. K. \& Yüksel, M. E. (2020). Accurate diagnosis of term-preterm births by spectral analysis of electrohysterography signals, Comput. Biol. Med., 119, doi: 10.1016/j.compbiomed.2020.103677.

Euliano, T. Y., Nguyen, M. T., Darmanjian, S., McGorray, S. P., Euliano, N., Onkala, A., \& Gregg, A. R. (2013). Monitoring uterine activity during labor: a comparison of 3 methods. American journal of obstetrics and gynecology, 208(1), doi: 10.1016/j.ajog.2012.10.873.

Fele-Žorž, G., Kavšek, G., Novak-Antolič, Ž., \& Jager, F., (2008). A comparison of various linear and non-linear signal processing techniques to separate uterine EMG records of term and pre-term delivery groups, Med. Biol. Eng. Comput., 46 (9), doi: 10.1007/s11517-008-0350-y.

Greenough, A. (2013). Long-term respiratory consequences of premature birth at less than 32 weeks of gestation, Early Hum. Dev., 89, doi: 10.1016/j.earlhumdev.2013.07.004.

Idowu, I. O. (2017). Classification Techniques Using EHG Signals for Detecting Preterm Births, PHD thesis, Liverpool John Moores University. 
Jager, F., Libenšek, S., \& Geršak, K., (2018). Characterization and automatic classification of preterm and term uterine records, PLoS One, 13 (8), doi: 10.1371/journal.pone.0202125.

Kenny L. C. \& Myers, J. E. (2020). OBSTETRICS | 20th EDITION by Ten Teachers, Lippincott Williams \& Wilkins: U.S.A.

Khalil M. \& Duchêne, J. (2000). Uterine EMG analysis: A dynamic approach for change detection and classification, IEEE Trans. Biomed. Eng., 47(6), doi: 10.1109/10.844224.

Léman, H., Marque, C. \& Gondry, J. (1999). Use of the electrohysterogram signal for characterization of contractions during pregnancy, IEEE Trans. Biomed. Eng., 46(10), doi: 10.1109/10.790499.

Lucovnik, M., Chambliss, L. R., Blumrick, R., Balducci, J., Gersak, K., \& Garfield, R. E. (2016). Effect of obesity on preterm delivery prediction by transabdominal recording of uterine electromyography, Taiwan. J. Obstet. Gynecol., 55 (5), doi: 10.1016/j.tjog.2015.05.005.

Maner, W. L., Garfield, R. E., Maul, H., Olson, G., \& Saade, G. (2003). Predicting term and preterm delivery with transabdominal uterine electromyography, Obstet. Gynecol., 101(6), doi: 10.1016/S0029-7844(03)00341-7.

Muszynski, L.C. (2019). Évaluation de l'électrohystérogramme pour la surveillance et le diagnostic des femmes à risqué d'accouchement premature, PHD thesis, Université de Technologie de Compiègne.

Verdenik, I., Pajntar, M., \& Leskošek, B. (2001). Uterine electrical activity as predictor of preterm birth in women with preterm contractions, Eur. J. Obstet. Gynecol. Reprod. Biol., 95(2), doi: 10.1016/S0301-2115(00)00418-8.

Ye-Lin, Y., Garcia-Casado, J., Prats-Boluda, G., Alberola-Rubio, J., \& Perales, A. (2014). Automatic identification of motion artifacts in EHG recording for robust analysis of uterine contractions, Comput. Math. Methods Med., doi: 10.1155/2014/470786.

Yochum, M., Laforêt, J., \& Marque, C., (2016). An electromechanical multiscale model of uterine pregnancy contraction, Comput. Biol. Med., 77, doi: 10.1016/j.compbiomed.2016.08.001 